\title{
Relationship between bone mineral density and balance disorders in osteoporotic patients
}

\author{
Fatemeh Radaei and Shahriar Gharibzadeh* \\ Neural and Cognitive Sciences Laboratory, Biomedical Engineering Faculty, Amirkabir University of Technology, Tehran, Iran \\ *Correspondence: gharibza@aut.ac.ir \\ Edited by: \\ Ridha Hambli, Polytechnique Orléans, France
}

Keywords: bone mineral density, the center of the mass, bone loss, instability, osteoporotic patients

It is known that due to decreasing bone formation, Bone Mineral Density (BMD) decreases in osteoporotic patients (Bone et al., 2000). In addition, some researchers have shown that osteoporotic patients suffer from balance disorders and increasing risk of falls (Sinaki et al., 2005).

Basically, five factors determine one's level of stability and mobility: (1) size of the base of support, (2) height of the center of mass, (3) location of the center of mass projection within the base of support, (4) body mass, and (5) friction (Whiting and Rugg, 2005). In some researches, it has been mentioned that height of the center of the mass decreases in osteoporotic patients, but its effect on instability of the patients is not significant, and in osteoporotic cases, there will be a great reduction in body mass, which has a negative effect on their stability (Ludlow, 2006). Researches have not mentioned the change of size of the base of support and friction (first and five factors).

Based on the above-mentioned points, we think that factors 1 and 5 will not change. In addition, we hypothesize that in osteoporotic patients, who have less BMD in comparison to age matched healthy individuals, center of mass of their bones and as the result, center of mass of their body have changed, so the location of their center of mass projection within the base of support changes. Hence, osteoporotic patients have balance disorders while standing or walking and risk of falls is high among them. It is proposed that they wear special shoes in order to compensate the change of center of mass projection to reduce the risk of falls, and their shoes should be provided with more frictional resistance at the interface between the ground and any contact point to increase their stability. Surely experimental researches and clinical trials are needed to validate our hypothesis.

\section{REFERENCES}

Bone, H. G., Greenspan, S. L., McKeever, C., Bell, N., Davidson, M., Downs, R.W., et al. (2000). Alendronate effects in postmenopausal women with low bone mineral density: Alendronate/Estrogen Study Group. J. Clin. Endocrinol. Metab. 85, 720-726. doi: 10.1210/ jc. 85.2 .720
Sinaki, M., Brey, R. H., Hughes, C. A., Larson, D. R., and Kaufman, K. R. (2005). Balance disorder and increased risk of falls in osteoporosis and kyphosis: significance of kyphotic posture and muscle strength. Osteoporos. Int. 16, 1004-1010. doi: 10.1007/s00198-004-1791-2 Whiting, W.C., and Rugg, S. (2005). Dynatomy: Dynamic Human Anatomy, 1st Edn. Champaign: Human Kinetics.

Ludlow, J. (2006). Osteoporosis - Weighing in on Aging Bones: Excessive Weight Loss and Age-Related Structural Change May Contribute to Fracture Risk. Medical News Today. Available at: http://www.medicalnewstoday. com/releases/44626.php

Received: 28 July 2013; accepted: 15 August 2013; published online: 19 September 2013.

Citation: Radaei Fand Gharibzadeh S (2013) Relationship between bone mineral density and balance disorders in osteoporotic patients. Front. Bioeng. Biotechnol. 1:5. doi: 10.3389/fbioe.2013.00005

This article was submitted to Biomechanics, a section of the journal Frontiers in Bioengineering and Biotechnology. Copyright (c) 2013 Radaei and Gharibzadeh. This is an open-access article distributed under the terms of the Creative Commons Attribution License (CC BY). The use, distribution or reproduction in other forums is permitted, provided the original author(s) or licensor are credited and that the original publication in this journal is cited, in accordance with accepted academic practice. No use, distribution or reproduction is permitted which does not comply with these terms. 